\title{
Customizing IT Service Agreements as a Self Service by means of Productized Service Propositions
}

\author{
Henrik Brocke \\ University of St.Gallen \\ henrik.brocke@unisg.ch
}

\author{
Falk Uebernickel \\ University of St.Gallen \\ falk.uebernickel@unisg.ch
}

\author{
Walter Brenner \\ University of St.Gallen \\ walter.brenner@unisg.ch
}

\begin{abstract}
Whilst service providers of information technology (IT) seek to achieve cost-efficiency and optimization in request processing, customers increasingly demand flexibility and agility to align long lasting IT service relationships to changing requirements of their business processes. Customer individual adjustments of service agreements and changes in commitments of functionality and performance cause negotiation and service reengineering efforts. Amounts of service agreements and change requests impede the overview of currently valid commitments in service systems. In order to overcome these problems, this article proposes to customize service systems on demand only by selecting, parameterizing and arranging predefined and productized service propositions. A self-service reference model is introduced that allows the customer to continuously adjust service systems in their arrangements of committed IT service propositions on demand. Its implementation as an online portal supports easy traceability of the current total of IT service commitments as well as consistency of additional service requests with the current service arrangement. Examples from its application in two major IT-projects illustrate the results.
\end{abstract}

\section{Introduction}

The research field of Service Science shifts the focus in service research toward ongoing value-cocreation and customer-orientation [1] and on continuous adjustment of service systems [2]. Its interdisciplinary approach longs for integrated consideration of flexible, business-oriented IT service management and design $[3,4]$. Thus, we focus on the business-oriented management of ongoing IT service systems, i.e. configurations of an IT provider and a customer organization to create value by IT service cocreation. Thereby, an IT service is understood as a set of related functions cocreated in a specific quality for managing and processing information to support one or more customer business processes [cf. 5].
Administration of such IT service systems is a complex, time-consuming and expensive task for both the IT provider and the customer organization especially as business-orientation demands the alignment of IT service agreements to business processes [6-8]: firstly, negotiation efforts occur with every service agreement to be contracted and every subsequent change request that occurs depending on changing requirements of the customer's business. Each time the customer organization must be asked for all data necessary for providing the requested service which often results into time-consuming information queries due to lacking specification and verification of the data asked for. Moreover, such additional service requests and changes must align with the current agreement situation. However, transparency and traceability of commitments currently valid in an IT service relationship becomes quite difficult with the rising amount of additional service and change requests, often resulting in a mess of interdependent agreements $[9,10]$.

As a result this lack of traceability does not only impede contracting of additional services and changes compatible to existing commitments, it furthermore makes it difficult to trace the compliance of commitments and performance [11]. While current IT management tools report performance measurement data of technical services (such as capacity or uptime) [cf. 12], transparency on the business level of processes supported by IT is still lacking an applicable IS-support basis. The same is true for transparency of contracted commitments at the provider's side. While solutions like the Configuration Management Data Base (CMDB) of the IT Infrastructure Library (ITIL) allow items to be allocated to resources [13], their link to business-oriented commitments in agreements is lacking [11].

Finally, the customer's users themselves as receivers of the service lack transparency in what commitments have been agreed-upon, often resulting in dissatisfaction of the service delivered [14]. 
Addressing these challenges, research as well as frameworks like the ITIL propose to standardize IT service catalogs and make them available for order as a self-service portal [15, 16]. However, research and practice lack support in mechanisms, guidelines and data structures for implementing such a solution. The work on hand addresses this gap by introducing tasks to be supported by a self-service portal by means of techniques, the roles executing these activities, as well as the data required. Thus, the work follows the specification principles of Method Engineering [cf. 17] according to Heym [cf. 18] and is part of an IT service management procedure that is introduced in [19]. The resulting self-service model for administrating IT service relationships the work on hand proposes serves as reference model in accordance with [20,21].

The reference characteristic builds on the model's implementation in two voluminous projects in cooperation with multiple IT service providers by Action Research as detailed in section 2. Building on research foundations in portals and in specification of standardized IT services, section 3 introduces a way to permanently request adaptions of the service relationship via predefined and well-engineered parameterized service propositions by means of a selfservice. Thus, customers may continuously trace, change, and configure ongoing core IT service agreements to their current business requirements. The subsequent sections 4 to 6 detail the activities of (1) information gathering, (2) tracing and (3) requesting of IT services via a self-service portal. The data required for executing these activities is modeled in section 7 , whilst section 8 concludes the work on hand and discusses its limitations.

\section{Research process and project scope}

This research arises from close collaboration with four IT providers over the last years. Due to the direct interaction between academic researchers and representatives of the corporations, 'action research' is the appropriate research method in accordance with $[22,23]$. The whole action research cycle has been iterated twice in joint action in the context of two voluminous, several month taking projects in cooperation with a worldwide operating ICT provider with more than nine billion USD of revenue in 2009. The aim of both successive projects was a proof-ofconcept by applying our service management procedure for IT providers - at first by prototyping a solution, and then by piloting it with customers.

One of the areas of research was the development of predefined, standardized on-demand service propositions that represent all customer requests and interactions allowing to request them via a self-service portal. Therefore, all customer specific changes in functionality and sizing were to be defined in advance. Based on insights from our SLA analysis and multiple in-depth interviews with IT Managers, we identified the need to create service propositions - in addition to the core IT service offerings - that represent all standard changes and customer (data) interactions within the life cycle of an IT service. The engineering of appropriately aligned service propositions was developed in several iterations and the resulting concept was iteratively refined based on experiences made. In addition, two self-service portals were developed allowing to leverage the potentials and opportunities resulting from increased traceability and consistency of service agreements. Expert interviews with representatives from both the IT provider organizations and their customer organizations were conducted to validate usability, enhanced customer orientation and opportunities for operational process standardization. Aiming at cross-organizational feedback, six workshops, each one comprising several IT organizations, were held for review on the conceptual basis, the process, and the outcomes. Moreover, five customer organizations were asked for their feedback by interviews and paper-based questionnaires.

\section{Foundations}

Aiming for a reference self-service portal for fully administrating customer-provider IT service relationships, two fields of foundations arise as detailed in the two following subsections: first, tasks and types of interactions to be supported by the portal are derived from literature. Secondly, for standardizing IT services, the work on hand builds on service productization in order to enable standardized request processing by means of a self-service portal.

\subsection{Supporting service relationship adminis- tration by means of a self-service portal}

Portals are used for inter-organizational collaboration with suppliers and customers in many different ways [24] and over decades [25]. They provide internal and external users with role-based, process-oriented access to a comprehensive set of services [26] while their ability to filter, target and categorize information enables users to get only what they need [27] on a single point of access [28, 29]. Improved customer retention, improved process efficiency and cost reduction are cited as main improvement potentials [30, 31]. Aiming for exactly these gains, a portal for administrating IT service relationships seems promising. 
For acting as a single point of contact between the customer organization and the IT service provider, all possible interactions and information demanded need to be identified and considered in a reference portal for enhanced IT service relationship management. In order to determine what interactions and mechanisms should be supported by such a portal, this work takes the Customer Buying Cycle [32, 33] into account. Representing the stages of a customer-supplier relationship the Customer Buying Cycle serves as checklist what interactions and mechanisms may potentially be enhanced by information systems [33] - such as portals as information systems by definition [26]. A literature review on service cycles and their potential support by portals as summarized in Table 1 revealed twelve tasks to be considered for a reference self-service portal as we aim for in the field of IT service relationships. The tasks can be categorized into three groups: browsing information about the service offering, tracing the current service relationship, and configuring and requesting additional IT services (cf. Table 1). Each of the three types is detailed in one of the sections 4 to 6 and illustrated in Figure 1 in regard to their tasks, techniques, input/output data, and executing roles.

Table 1: Tasks to be supported by means of a portal along the service lifecycle

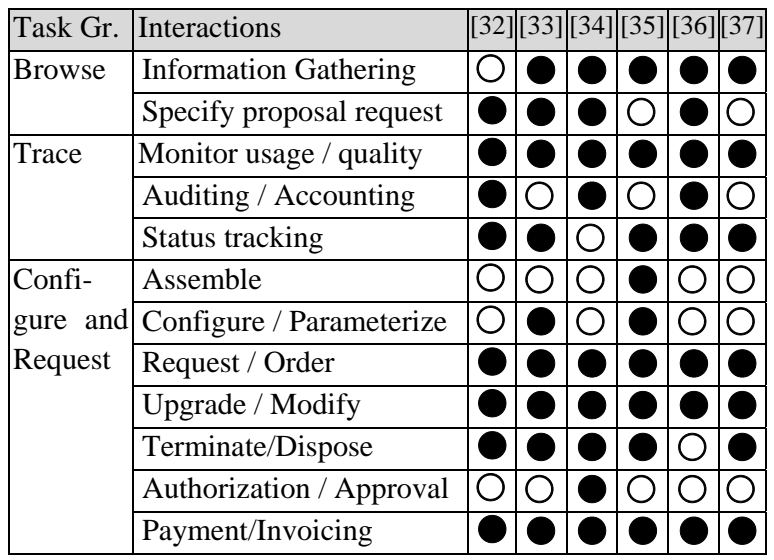

\subsection{Productizing IT service propositions}

Evolving business environments require the continuous adaption of a service system's stipulated service agreement to changing demands [38]. In order to decrease costs and increase efficiency of change and adjustment procedures, this article proposes the usage of predefined service propositions that change the actual core service agreement as to allow for continuous customizability according to the evolving requirements of the customer's business. With that, the article builds on the growing paradigm of serviceoriented thinking in IT, which until now focuses on application development and Software as a Service in order to create a basis for agility and harness the service value approach from a customer's perspective [39]. Simultaneously, it addresses the rising demand for on-demand service request processing as pushed by the actual topic [12] of cloud computing [40].

As a portfolio-analysis of IT providers shows, some service offers already serve the purpose of changing or configuring an ongoing service agreement at run time [41]. The ITIL labels such service requests Standard Changes [42, p.48]. Although common in the area of client and desktop provision, the analysis showed that hardly any of such standard changes is fully predefined with regard to the processes of provision and operations or defined precisely enough to compensate for further requirement analyses.

Aiming for efficiency and cost reduction, the general principle of service productization tries to overcome this lack of sufficient pre-engineering of service offerings. Having adopted the term from the industrial [43-45] to the IT service sector, IT service offerings shall be predefined with regards to both their commitments and the operational procedures to provide them [46-48]. The ultimate goal of such predefined 'potential models' [49] is thereby to offer both business orientated and standardized value propositions. However, while this appears realizable in the software-industry [50, 51], IT service agreements in complex IT service systems seem too customerindividual to allow service productization: originally standardized service offers are often "customized beyond recognition“ [10] - contradicting calls for standardization and reduced negotiation efforts. Evolving market structures in the customer's business and associated requests for adjusting the IT service agreements to changing demands result in change requests and thus require reengineering activities of originally standardized service propositions.

In order to enable standardized self-service request processing and reduce negotiation efforts, this article enhances the concept of productization to cover all interactions between customer and provider via productized service propositions. This would include the productization of continuous service adjustment requests after the initial agreement: in contrast to a productized core service proposition, which describes a long-lasting, process related, basic overall IT service offer that supports a business process, additional productized complementary service propositions are declared that cover all available changes of commitments concerning functionality and quality issues [cf. 52]. Therefore, the arrangement of agreed-upon complementary service propositions configures or modifies the IT service system in its core service agreement. 
In analogy to a physical product's characteristics, productized complementary service propositions are well-defined in functionality and performance, documented in a catalogue, priced and ready to be agreed-upon along the ongoing core service cocreation. All information that is necessary for processing the cocreation is predefined and prompted when the proposition is agreed-upon. Furthermore, the productization allows for agreeing upon reference numbers instead of textual change requests and therefore provides the opportunity to standardize the agreement processing as well as IT-operations processes. Finally, the productization of service propositions allows providing an overview of a service system's currently arranged, i.e. agreed-upon propositions as well as their agreement history - which is labeled the service system's agreed-upon 'service arrangement'. It consists of a number of selected, parameterized instances of service propositions that represent contracted commitments. The continuous possibility for adaption of the service arrangement is termed 'service arrangement configuration'. It exclusively occurs within the scope of a previously agreed-on service catalogue and is applied in the last of three subsequent phases of customer interaction along the service lifecycle, namely service design, service contracting and service arrangement [cf. 53, 54].

At the phase prior to the service arrangement configuration, a master agreement is contracted that specifies which service propositions are available for configuring the service arrangement. Thus, a customerindividual pre-selection of service propositions is contracted. If customer requirements differ from existing service propositions, the IT service provider may decide to specify additional, new service propositions according to the customer's requirements [55]. This is done at the stage of service design. As a result, three configurational steps or phases can be identified, which are performed consecutively in order to comply with the individual customer requirements and to maintain the standardization of IT operations. This article is confined to introduce and explain the support of activities in the last stage of service arrangement configuration by means of a self-service portal, while the prior phases of service design and contracting are further detailed in [19]. Thus, each of the three following sections details one group of tasks to be supported by a portal as identified in section 3.1.

\section{Browsing the service directory}

One of the main tasks an online-portal for IT services should support is to inform the users on the offering of potential services they may request. As workshops with four cooperating IT providers revealed, one of the main reasons for unsatisfied users is that they may trace neither agreed-upon commitments nor possible adjustments by requesting complementary service propositions. In order to resolve this lack of transparency, not only the customer's Demand-IT department should have access to the self-service portal but all users of the customer's functional departments whose task requires IT support. Therefore, the service directory offered in the portal does not include all services offered, but exclusively displays those service propositions pre-selected and contracted in a masteragreement with the Demand-IT department. However, users may request for additional service proposals, potentially resulting in a process of service design and extension of the master-agreement [cf. 41]. Dependent on users' roles their view on the service directory is restricted to service propositions relevant for their task. Users may access service descriptions that are to be described in a user-oriented way as detailed in [56].

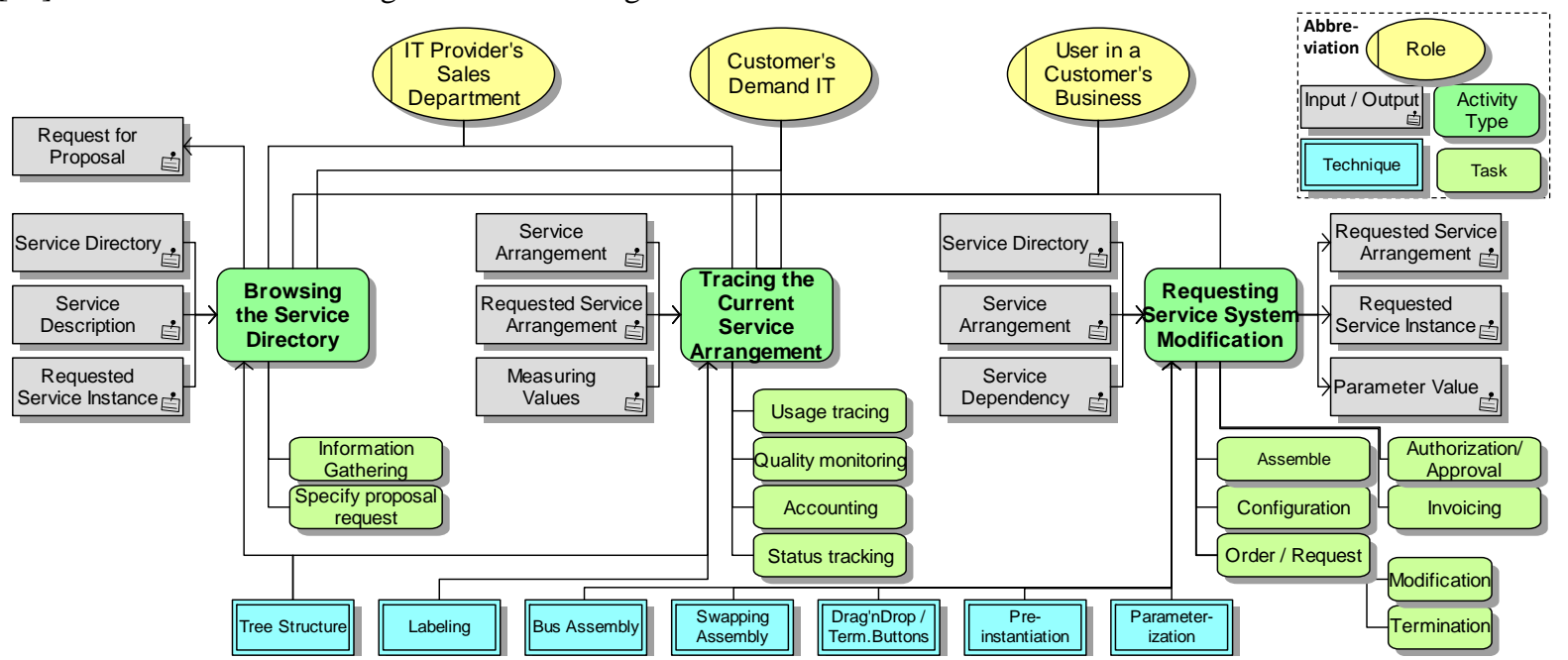

Figure 1: Three task groups of portal support with allocated tasks, roles and input/output data 


\section{Tracing the current service arrangement}

Easy traceability of the agreed-upon IT services - i.e. the service arrangement - is one of the main advantages of predefining and productizing all interactions between customer and IT provider as on-demand service propositions. Whilst nowadays usually paperbased master service agreements, SLAs, and change requests cause irreproducible commitment situations concerning validity, consistency and value-cost-ratio [9], visual representation of the service system's current service arrangement by an online portal would facilitate traceability of the actual commitment situation for both the IT provider and the customer. Once transparency in committed functionality and performance is achieved, it may be compared to the measured quality in order to trace compliance of commitments. Furthermore, services requested but not yet provisioned, as well as costs per service - including the management of unpaid invoices - should be traced by both the customer's users of IT-support as well as the IT service provider (cf. Figure 1).

Within the scope of our projects, visual representations of the service arrangement in a web based portal have been implemented for both parties according to their information requirements. The technique of displaying agreed-upon propositions as a tree-structure allows the customer to trace the total of commitments. Detailed information may be reported per service instance concerning agreement history, actual status and especially compliance of performance parameters over time. These tasks require data of the service arrangement, its measurement values as well as the requested but not yet provisioned services (cf. Figure 1).

The upper screenshots in Figure 2 show the webbased views on an arrangement of hosted applications (left side) and of end-to-end services for merchants (right side). Two hosted applications can be found in the tree-structure of the upper-left view, whilst their lower relations show their releases and, if demanded, each transport. The same is true for selected middleware components, which are related to the application's usage. Interfaces as well as functional extensions like 'extended support' are itemized and related to their application instance. Relating to the upper-right view, registered users are arranged according to their home location. Usable workplaces, related roles and extended functionality like online backup are subordinated to the users. For the IT provider, the views need to be extended to cover the related resources per agreed-upon service proposition that have been provisioned to provide the service potential. With that, the IT provider may not only trace the committed service arrangement, but also the actual allocation to resources. As seen on the lower screenshots: in order to provide the middleware 'SAPportal', a license, storage-amounts and a virtual server have been allocated. Furthermore, the service access for a dedicated workplace requires an exchange CAL and a license as shown on the figure's lower right side.

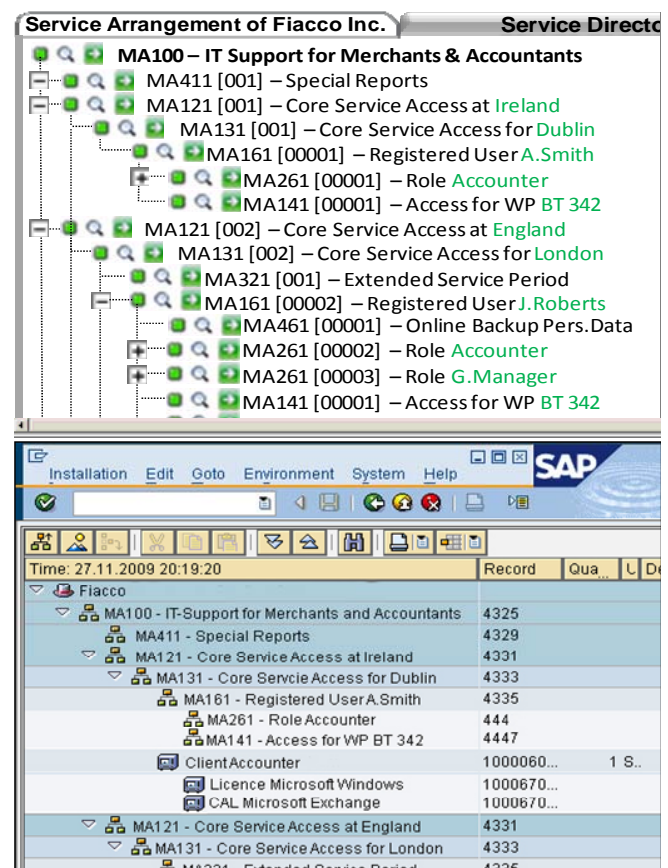

Figure 2: Separated views on the service arrangements of two service systems 


\section{Configuring the service arrangement}

Necessary adjustments or cancelations of the service arrangement resulting from the customer's changing business requirements may be covered by choosing, configuring, and ordering predefined complementary service propositions on demand. Aiming at standardized and efficient service provisioning, consistency with the actual service arrangement may be ensured by use of a self-service portal: the view on the directory of offered service propositions lists only those that are compatible with the current service arrangement.

The process of adjusting a current service arrangement according to changing business requirements by the customer's users builds on busassembly and swapping-assembly [57] and comprises 4 subsequent activities: the first step of the procedure consists in a specific service instance to be altered by additional commitments. Subsequently, additional service propositions are selected and then configured in parameters according to the customer's requirements. Finally the resulting configuration is requested and provisioned. As Figure 1 illustrates, this process builds on the current service arrangement data and results in an updated service arrangement, containing additional service instance requests and their parameter values. In the following, each activity and outcome is discussed.

\subsection{Browsing service instances to be adjusted}

Since service propositions may be dependent on the existence of service instances, in a first step a specific service instance to be altered by additional commitments must be selected. This task builds on the views on the current service arrangement as described in section 5: they are used in order to browse the service instances and select the one that shall be altered or enhanced in its commitments. For example, a service instance that supports a specific location of the customer's business with IT may be extended in its commitments in regards to faster operations at this location. This selection of existing service instances as required reference for additional requests of service propositions ensures transparency and clarity of agreed-upon commitments since the customer may later trace added services.

In order to separate the service selection form potentially crowed service arrangement views, it has been implemented in our service portals by dragging and dropping a service instance from one part of the screen that shows the entire service arrangement to a second one called 'workspace', as Figure 3 shows the selection of the service access for Dublin.

\subsection{Selecting additional service propositions}

Dependent on the selection of a service instance, the view on the service propositions offered is reduced: based on service dependency data, it shows only those propositions that may consistently be requested in the context of the respective service instance. The resulting list of consistent service propositions may now be used to select one or more propositions in order to extend or change the commitments. Although not being provided yet, the selected service propositions are then preinstantiated, i.e. handled as service instances - thus allowing the customer to select additional service propositions based on the already chosen ones. Thus, a bundle of interrelated service propositions can be chosen while assuring consistency in dependencies.

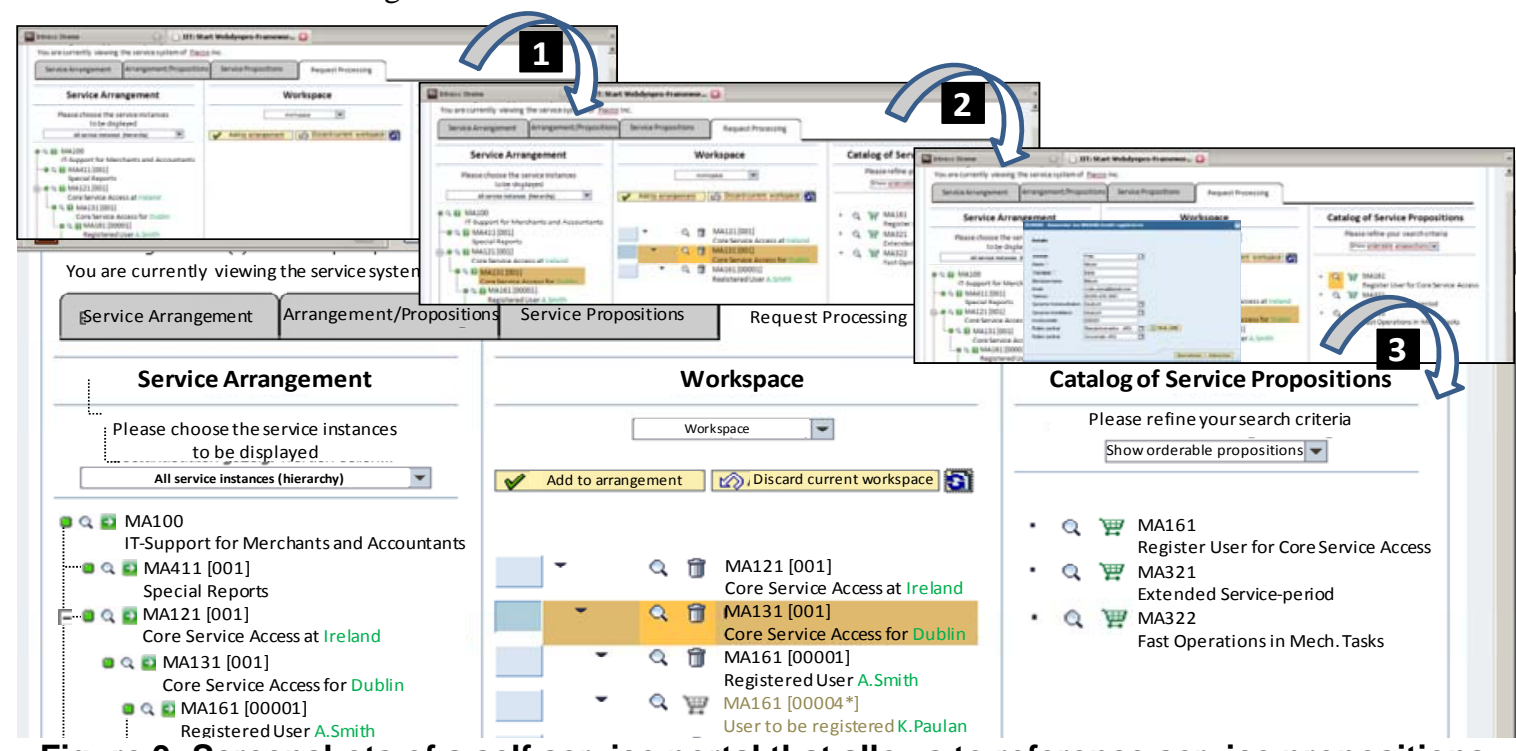

Figure 3: Screenshots of a self service portal that allows to reference service propositions 
For implementing the above described selection process, the layout of service portals requires three screen parts: while one displays the catalog of available service propositions, a second one shows the current service arrangement. As already introduced, an additional screen part serves as 'workspace' in order to help keeping the overview of selections. As for service instances, service propositions may be dragged and dropped into the 'workspace' area, which thus includes both service instances and selected but not yet provisioned service propositions. Service propositions used for requesting termination of a current service instance may be requested by termination buttons instead of drag'n drop. The screenshot series in Figure 3 illustrates one of the implementations.

\subsection{Configuring selected service propositions}

In order to enable efficient IT request processing, all customer individual data and characteristics of a service instance are entered by the customer in the process of service requesting. This activity represents the third step of the procedural service arrangement configuration. It assures that all data necessary for standardized, on-demand service request processing are entered at this point and in a consistent manner. The entered data may then serve as standardized parameters for customer individual service provisioning. Such a parameterization may e.g. include address data, the customer's role concept, or design of reports but also deployment data and scripts of interfaces or releases to be deployed. Additionally, references to other service instances must be entered as parameters when requesting a new service proposition. The parameters entered may also be used to individualize labeling of service instances as highlighted by green color in the service arrangement views of Figure 2 and 3. Names of locations and users, but also of applications and middleware provided may individualize the view. Thus, traceability of the individual service arrangement is substantially facilitated.

\subsection{Requesting and providing selected service propositions}

By requesting a certain modification of commitments once all selected service propositions are configured and parameterized, the resulting configuration of service propositions may be authorized and approved and thus be contracted. As the portal takes into account service dependencies and ensures that all data being entered to parameterize service propositions are complete, the requested commitment adjustment complies with the current service arrangement. Even if the thus requested services are not yet delivered and accessible, they are listed as service instances in the self-service portal's view on the service arrangement. However, in order to sustain easy traceability, they remain marked as 'not provisioned' until the committed service will be provided and subsequently be invoiced. Thus, they may already build the reference basis for additional service requests.

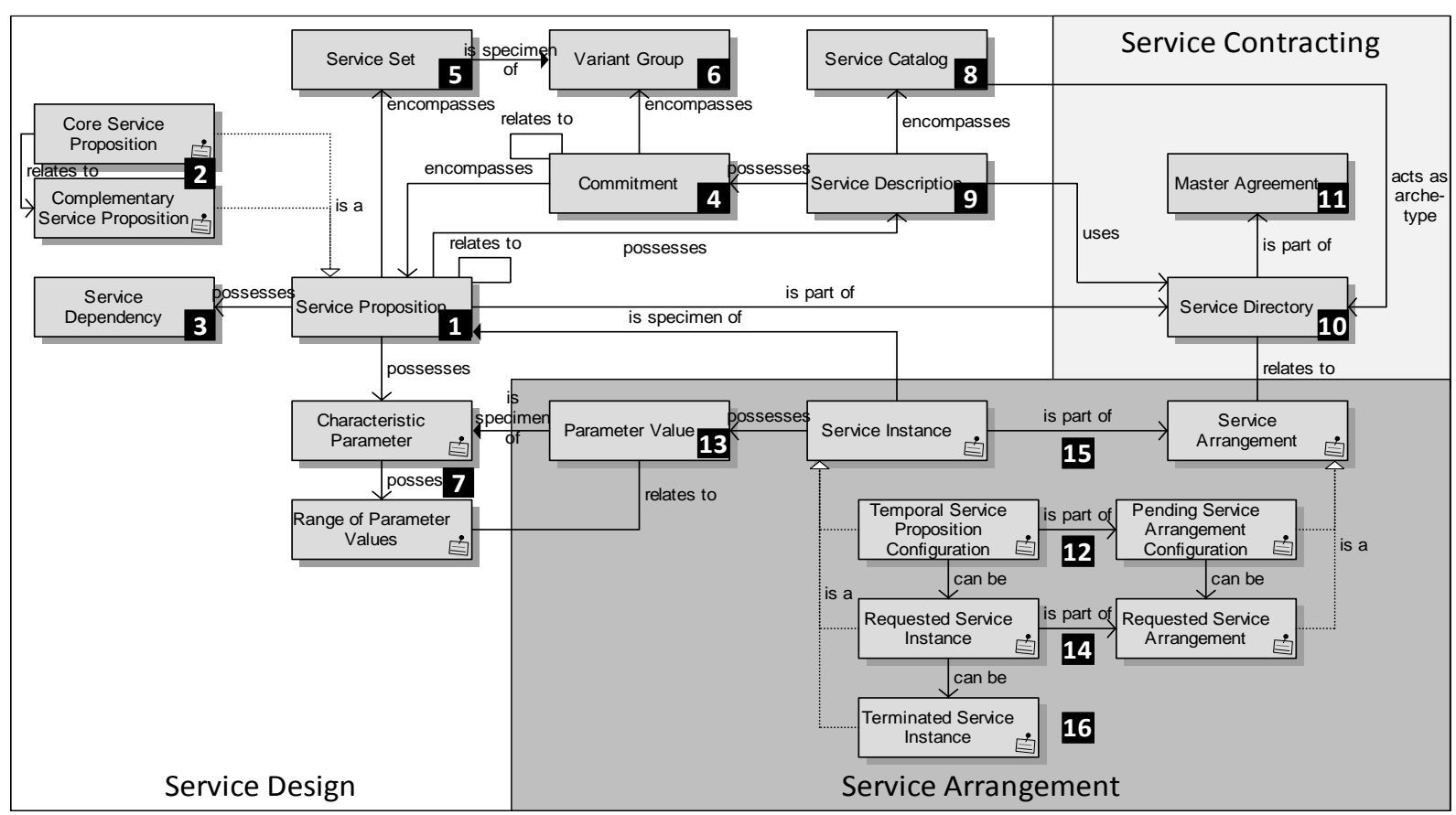

Figure 4: Information model of the introduced procedure for customizing IT service on demand 


\section{Information model}

Having introduced the activities, techniques and outcomes of the procedure's service arrangement configuration phase, the specification includes their data relations in a meta model [58], i.e. the information model of the results [59]. For the benefit of readability it is modeled as term diagram in ARIS [60].

Figure 4 shows the information model while differentiating between the three phases of service design, service contracting and service arrangement. Service propositions (1) may be of core or complementary type (2) whose interdependencies are explicit (3). They are composed by a structure of commitments (4) whose combination will result in different variants of interrelated service propositions so called service sets (5). The total number of declared variants of a certain service offer, originating from the same collection of commitments, is termed variant group (6). Parameters per service proposition declare the range of customization (7). A catalog of service propositions lists the IT provider's offering (8) that consists of user-oriented descriptions (9) of commitments in regard to functionality and performance.

The engineering process may either be initiated by the IT provider due to market research or else may result from specific business requirements of a customer. Once specified, a customer-specific preselection of service propositions is assembled on the basis of the service catalog. The resulting service directory (10) is contracted as part of a master agreement (11).

Once contracted, the customer may assemble service propositions in the range of the service directory. Therefore, a choice of service propositions (12) is to be parameterized according to customer requirements (13) and may then be requested and approved to be provided (14). The overall amount of requested service instances represents the current service arrangement (15) that may be traced by a self-service portal (cf. section 5). Therefore, data of both active and already completed customer requests (16) may be accessed by linked assignment relationships. Thus, continuous ondemand adjustment of the current service arrangement may be executed by additional service proposition configurations that may refer to existing service instances.

\section{Summary and limitations}

IT service agreements are often defined highly customer-specific and are subject to continuous change, resulting in high contracting efforts. Moreover, customer organizations as well as IT providers lack transparency in the currently contracted commitments of a service relationship and their costs due to amounts of interdependent change requests and service agreements. In order to resolve these difficulties and facilitate standardization of request processing, this article suggests to productize the service offering and to predefine complementary service propositions in order to allow the customization and continuous adjustment of IT service agreements on demand. The request for service propositions may either extend/reduce functionality or change current performance commitments. Thus, the customer's overall service agreement, i.e. service arrangement becomes precisely adjustable regarding valid time period and receiver. A view which is generated on the actual service arrangement provides transparency and traceability in the service currently agreed-upon as well as their respective expenses.

The article introduced a reference self-service for administrating IT service relationships as part of a procedural model how to design, contract and continuously adjust service agreements that build on productized service propositions. As a reference model its reuse is supposed to increase both effectiveness and efficiency when being applied or adapted in specific situations. A self-service portal enables the user to request additional service propositions consistent to the current service arrangement on demand. Examples of implemented self-service portals illustrated the model's application. An information model enhances the documentation to facilitate the model's application.

Our repeated implementation of the procedure and self-service portals resulted in high acceptance by and satisfaction of the customers, who attested a significant impact on the traceability and changeability of the service system. Moreover, IT-operation experts testified increasing standardization capabilities.

Nevertheless, our research is subject to several limitations. Our implementation sample size, although referring to major projects, is small. This puts into doubt whether the achievement of benefits is generalizable. In close research interaction with several IT providers, we aim at further implementing projects in order to gain additional findings and data for evaluation. In addition, usability-issues of the selfservice portal implementations call for further research.

Considering these research tasks, we belief that the productization of IT service propositions and the continuous on-demand adjustment of service arrangement via a self-service together enable the IT provider to increase both customer satisfaction and efficiency in IT-operations. 


\section{References}

[1] Van Bon, J., IT Service Management: An Introduction. 2007, Zaltbommel, Netherlands: Van Haren Publishing.

[2] Spohrer, J., et al., Steps toward a science of service systems. IEEE Computer Society, 2007. 40(1): p. 71-77.

[3] Chesbrough, H. and J. Spohrer, A Research Manifesto for Services Science. Communications of the ACM, 2006. 49(7): p. 35-40.

[4] Maglio, P.P., et al., The Service System Is the Basic Abstraction of Service Science. Information Systems and eBusiness Management, 2009. 7(4): p. 395-406.

[5] Rodosek, G.D. A generic model for IT services and service management. in Integrated Network Management, IFIP/IEEE Eighth International Symposium. 2003.

[6] Peppard, J., Managing IT as a Portfolio of Services. Eur Manage J, 2003. 21(4): p. 467-483.

[7] Nieminen, P. and T. Auer, Packaging of IT services, in TUCS Technical Report. 1998, Turku Centre for Computer Science: Turku, Finland.

[8] Keel, A.J., et al., From a technology-oriented to a service-oriented approach to IT management. IBM Systems Journal, 2007. 46(3): p. 549-564.

[9] Karten, N., With Service Level Agreements, Less is More. Information Systems Management, 2004. 21(4): p. 43 - 44.

[10] Hradilak, K.P., Führen von IT-Service-Unternehmen. 2007, Wiesbaden: Vieweg.

[11] Ernest, M. and J.M. Nisavic, Adding value to the IT organization with the component business model. IBM Systems Journal, 2007. 46(3): p. 387-403.

[12] Govekar, M., et al., Hype cycle for IT operations management. 2009, Gartner Research.

[13] OGC, ITIL - Service Operation. IT Infrastructure Library. 2007, Norwich: The Stationery Office (TSO).

[14] Unterharnscheidt, P. and A. Kieninger. Service Level Management - Challenges and their Relevance from the Customers' Point of View. in Proceedings of the 16th Americas Conference on Information Systems (AMCIS). 2010. Lima, Peru.

[15] OGC, ITIL - Service Design. IT Infrastructure Library. 2007, Norwich: The Stationery Office (TSO).

[16] Curtis, D. and K. Brittain, Document the IT Service Portfolio Before Creating the IT Service Catalog. 2009, Gartner Inc.

[17] Braun, C., et al. Method Construction - A Core Approach to Organizational Engineering. in Proceedings of the ACM Symposium on Applied Computing. 2005. Santa Fe, New Mexico: ACM.

[18] Österle, H. and D. Blessing, Business Engineering Model, in Business Engineering, H. Österle and R. Winter, Editors. 2000, Springer: Berlin. p. 61-82.
[19] Brocke, H., F. Uebernickel, and W. Brenner, Balancing Customer Requirements and IT Service Standardization: A Procedural Reference Model for Individualized IT Service Agreement Configurations. Enterprise Modelling and Information Systems Architectures, 2010.

[20] Fettke, P. and P. Loos, Classification of reference models: A methodology and its application Information Systems \& E-Business Management, 2003. 1(1): p. 35-53.

[21] Rosemann, M. and W.M.P. Van der Aalst, A configurable reference modeling langurage. Information Systems, 2007. 23(1): p. 1-23.

[22] Gummesson, E., Qualitative Methods in Management Research. 2nd ed. 2000, Thousand Oaks, CA, USA: Sage Publications.

[23] Checkland, P. and S. Holwell, Action Research: Its Nature and Validity. Systemic Practice and Action Research, 1998. 11(1): p. 9-21.

[24] Kalakota, R. and M. Robinson, e-Business 2.0: Roadmap for Success. 2001, Boston, MA: Addison Wesley Longman.

[25] Bristow, P., et al., Enterprise Portals: Business Application and Technologies. 2001, East Yorkshire: Butler Group.

[26] Dias, C., Corporate Portals: A Literature Review of a New Concept in Information Management. International Journal of Information Management, 2001. 21(4): p. 269287.

[27] Eckel, R., A road map to identify the portal for your company. DM Direct Journal, 2000. 14(July): p. 11-15.

[28] Anneja, A., B. Brooksby, and C. Rowan, Corporate portal framework for transforming content chaos on intranets. Intel Technology Journal, 2000. 11(3): p. 21-28.

[29] Schroeder, J., Enterprise portals: a new business intelligence paradigm. MIS Quarterly, 2000. 23(9): p. 124126.

[30] Gillet, F.E., Making Enterprise Portals Pay. 2001, Forresster Research Inc.: Cambridge, MA.

[31] Puschmann, T.A., Rainer. Process Portals - Architecture and Integration. in Proceedings of the 37th Annual Hawaii International Conference on System Sciences. 2004. Hawaii.

[32] Ives, B. and G.P. Learmonth, The Information System as a Competitive Weapon. Communication of the ACM, 1984. 27(12): p. 1193-1201.

[33] Muther, A.Ö., Hubert, Electronic Customer Care. Wirtschaftinformatik, 1998. 40(2): p. 105-113.

[34] Piccoli, G.S., Bonnie R.; Ives, Blake, A Framework for Improving Customer Service through Information Technology, in Cornell Hotel and Restaurant Administration Quarterly. 2001, Cornell University.

[35] Cäsar, M., Service-Portale in Industrie-Unternehmen, in Institute of Information Management. 2005, University of St. Gallen: St. Gallen. 
[36] Gizanis, D., C. Legner, and H. Österle, Architektur für die kooperative Auftragsabwicklung, in Wirtschaftsinformatik 2005: eEconomy, eGovernment, eSociety, O. Ferstl, et al., Editors. 2005, Physica: Heidelberg. p. 43-62.

[37] Archer, N. and Y. Yuan, Managing business-to-business relationships throughout the e-commerce procurement life cycle. Internet Research: Electronic Networking Applications and Policy, 2000. 10(5): p. 385-395.

[38] Ivens, B.S., Flexibility in industrial service relationships: The construct, antecedents, and performance outcomes. Industrial Marketing Management, 2005. 34(6): p. 566-576.

[39] Demirkan, H., et al., Service-oriented technology and management: Perspectives on research and practice for the coming decade. Electronic Commerce Research and Applications, 2009. 7(4): p. 356-376.

[40] Leimeister, S., et al. The Business Perspective of Cloud Computing: Actors, Roles, and Value Networks. in Proceedings of the 18th European Conference on Information Systems (ECIS). 2010. Pretoria.

[41] Brocke, H., F. Uebernickel, and W. Brenner. Mass Customizing IT-Service Agreements - Towards Individualized On-Demand Services. in Proceedings of the 18th European Conference on Information Systems (ECIS). 2010. Pretoria, South Africa.

[42] OGC, ITIL. IT Infrastructure Library. 2007, Norwich: TSO.

[43] Flamholtz, E., Managing organizational transitions: implications for corporate and human resource management. Eur Manage J, 1995. 13(1): p. 39-51.

[44] Flamholtz, E.G. and Y. Randle, Growing pains: Transitioning from an entrepreneurship to a professionally managed firm. 2000, San Francisco: Jossey-Bass.

[45] Simula, H.L., Tuula; Salo, Jari. Re-thinking the product: from innovative technology to productized offering. in Proceedings of the 19th International Society for Professional Innovation Management Conference. 2008. Tours, France.

[46] Bullinger, H.-J., K.-P. Fähnrich, and T. Meiren, Service Engineering: Methodical Development of new Service Products. International Journal of Production Economics, 2003. 85(3): p. 275-287.

[47] Zarnekow, R. and W. Brenner. A product-based information management approach. in 11. European Conference on Information Systems (ECIS). 2003. Neapel.

[48] Salmi, P.T., Marko; Ojanen, Ville; Himola, Olli-Pekka, New product creation process of KIBS firms: A case study.
International Journal of Services and Standards, 2008. 4(1): p. 16-32.

[49] Thomas, O. and J. v. Brocke, A value-driven approach to the design of service-oriented information systems making use of conceptual models. Information Systems and e-Business Management, 2010. 8(1): p. 67-97.

[50] Alajoutsijärvi, K., K. Mannermaa, and H. Tikkanen, Customer relationships and the small software firm: A framework for understanding challenges faced in marketing. Information \& Management, 2000. 37(3): p. 153-159.

[51] Hoch, D.J., et al., Secrets of software success: Management insights from 100 software firms around the world. 2000, Boston: Harvard Business School Press.

[52] Brocke, H., F. Uebernickel, and W. Brenner. Managing the Current Customization of IT Service Agreements. in Proceedings of the 43th Hawaii International Conference on System Sciences (HICSS). 2010. Koloa, Hawaii, USA: IEEE Computer Society Press.

[53] Garschhammer, M., et al. Towards generic service management concepts: A service model based approach. in Proceedings of the 7th IFIP/IEEE International Symposium on Integrated Network Management. 2001. Seattle, WA, USA: IEEE Publishing.

[54] Hegering, H.-G., S. Beck, and B. Neumair, Integrated Management of Networked Systems: Concepts, Architectures, and their Operational Application. 1999: Morgan Kaufmann Pub.

[55] Bullinger, H.-J. and A.-W. Scheer, Service Engineering: Entwicklung und Gestaltung innovativer Dienstleistungen. 2. Aufl. ed. 2006, Berlin: Springer.

[56] Brocke, H., et al. Design Rules for User-Oriented IT Service Descriptions. in Proceedings of the 42nd Hawaii International Conference on System Sciences (HICSS). 2009. Waikoloa, Hawaii, USA.

[57] Brocke, H., F. Uebernickel, and W. Brenner. ReuseMechanisms for Mass Customizing IT-Service Agreements. in Proceedings of the 16th Americas Conference on Information Systems (AMCIS). 2010. Lima, Peru.

[58] Gutzwiller, T., Das CC RIM-Referenzmodell für den Entwurf von betrieblichen, transaktionsorientierten Informationssystemen. 1994, Heidelberg: Physica.

[59] Winter, R. and J. Schelp. Reference modeling and method construction: a design science perspective. in Proceedings of the ACM symposium on Applied computing. 2006. Dijon, France.

[60] Scheer, A.-W., ARIS - Business Process Modeling. Third Edition ed. 2000, Berlin, Germany: Springer. 